\title{
Trabalhonecessário
}

Issn: 1808 - 799X

ano 10, no 14 - 2012

\section{ORGANISMOS SUPRANACIONAIS: A CONSTRUÇÃO DE UMA CONCEPÇÃO DE MUNDO EM TORNO DA INTEGRAÇÃO DA EDUCAÇÃO SUPERIOR - O CASO DO BRASIL ${ }^{1}$}

\section{Resumo}

Zuleide S. Silveira ${ }^{2}$

Neste texto, examinamos o papel dos organismos supranacionais e suas mediações com Estado brasileiro, ao assumirem papel decisivo nas orientações de ordem política, assistência técnica, metodológica e financeira no que diz respeito à "reestruturação", "modernização", "desenvolvimento econômico", "democratização" dos EstadosNações, "democratização da educação" e "internacionalização da educação superior", com vistas à reforma cultural, intelectual e moral da sociedade. Buscamos evidenciar que a base de ação desses organismos se pauta nos acordos multilaterais entre Estados e bloco de Estados, tornando-se, desse modo, mediação para os processos de internacionalização da economia e da tecnologia, em geral, e da educação superior, em particular.

Palavras-chave: Organismos Supranacionais - Estados-Nações - Educação Superior

\section{INTRODUÇÃO}

A internacionalização da economia, compreendida como internacionalização do processo produtivo e, portanto, da tecnologia, envolve a internacionalização do trabalho e seu correlato, a educação.

No século XIX, Marx e Engels (2004) já apontavam para a internacionalização do conhecimento como processo concreto, decorrente da natureza tendencial do capitalismo de se expandir globalmente em busca de novos mercados, que engendra certo tipo de universalização da interdependência das nações na produção intelectual.

Concordamos, pois, com Sguissardi (2005, p.7) quando afirma que seria ingenuidade pensar a globalização como algo restrito ao âmbito econômicofinanceiro, pois que envolve também as dimensões da sociedade,

\footnotetext{
${ }^{1}$ Este texto tem por base Silveira (2011).

2 Doutora em Educação/Campo Trabalho e Educação (UFF); Professora Associada do Núcleo de Estudos, Documentação e Dados sobre Trabalho e Educação (NEDDATE/UFF); Professora de Sociologia Aplicada do Curso Técnico de Segurança do Trabalho; Professora de Economia Política da Educação do Curso de Pós-Graduação Lato Senso Trabalho, Tecnologia e Educação, ambos do CEFET/RJ; zuleidesilveira@terra.com.br
} 
particularmente a educacional e cultural. Seria, portanto, cometer um erro teórico metodológico imaginar que a "mundialização do capital" (CHESNAIS, 1996), invasora de todas as dimensões da sociedade não invadiria, com força maior hoje do que ontem, a universidade.

O processo crescente internacionalização das políticas educacionais e de seu correlato, a internacionalização do conhecimento, vem sendo examinada por vários pesquisadores na América Latina. No Brasil, destacamse Coggiola (2001; 2004; 2005), Lima (2006; 2007); Neves (2006), Neves; Pronko (2008), Sguissardi (1998; 2002; 2005), Siqueira (1995; 2004; 2006a; 2006b), entre outros.

Enfatiza-se, com base na teoria do sistema mundial ${ }^{\beta}$ de Immanuel Wallerstein, o desenvolvimento de um modelo de escola moderna, inscrita em uma dinâmica histórica da expansão da produção e do mercado mundial capitalistas, que se opõe a qualquer forma pré-moderna de instrução.

A educação, como um fenômeno que se internacionaliza, compreende a expansão da escolarização de massas para patamares mais altos de ensino, a difusão da ideologia da modernização e do desenvolvimento econômico, as relações de cooperação e intercâmbio científicos entre os sistemas nacionais de ensino, a educação comparada e, sobretudo, a mediação das organizações supranacionais $\square$ UNESCO, OCDE, BM, BID, FMI, OMC, OIT, USAID, Fundação Européia da Cultura, Fundação Ford, Fundação Rockfeller e Fundação Carnegie, bem como entidades de caráter regional, a exemplo da CEPAL, OREALC, MERCOSUL, no âmbito da América Latina, com o que os diferentes Estados-Nações têm redefinido, dentro do atual estágio de acumulação capitalista, o papel da escola, particularmente o da universidade.

Ressalte-se que os blocos econômico-regionais, fenômeno que não pode ser negligenciado, têm sido analisados como instituições supranacionais, cuja base de ação se pauta nos acordos multilaterais entre Estados, tornando-

\footnotetext{
${ }^{3}$ A teoria do sistema mundo capitalista, pensada originalmente por Immanuel Wallerstein, seguida por Giovanni Arrighi, Samir Amin, André Gunder Frank e Theotonio dos Santos, analisa a formação e o desenvolvimento do modo de produção capitalista como um sistema de relações econômico-sociais, políticas e culturais, originado na Europa, em fins na Idade Média, que se expande mundialmente, trazendo como traço marcante a existência de um centro, uma periferia e uma semiperiferia nas suas relações dialéticas. Essa análise do desenvolvimento de longo tempo do sistema mundial capitalista combina perspectivas dos ciclos econômicos de longo prazo de Kondratiev e dos ciclos históricos de Fernand Braudel.
} 
se, desse modo, mediação para os processos de internacionalização da economia, tecnologia e educação, ao mesmo tempo em que se apresentam como instâncias que criam, modelam, filtram e veiculam esses processos. Como exemplo, podemos citar a União Europeia e o MERCOSUL, que representam as formas institucionais mais avançadas neste domínio.

Funcionando como mecanismo de interpenetração e desdobramento dos conteúdos políticos, econômicos e culturais do imperialismo, os organismos supranacionais, tidos neste texto como partido político (GRAMSCI, 2007), mediados pelos Estados-Nações, burguesias dependentes associadas ao capital internacional, intelectuais tradicionais e orgânicos, assumem papel decisivo nas orientações de ordem política, assistência técnica, metodológica e financeira no que diz respeito à "reestruturação", à "modernização", ao "desenvolvimento econômico", à "democratização" dos Estados-Nações, "democratização da educação"; "internacionalização da educação superior", com vistas à reforma cultural, intelectual e moral da sociedade.

Considerando que a ideologia desenvolvimentista conjuga desenvolvimento, paz e segurança (CARDOSO, 1978), na perspectiva holística dos organismos supranacionais, o crescimento econômico, sob as bandeiras da "inclusão social", do "combate à pobreza" e do "combate às desigualdades na educação", busca afirmar o capitalismo como um modo de relação social e produção insuperável, escamoteando, assim, o antagonismo entre classes.

Portanto, os organismos supranacionais, tanto na estrutura, quanto na política, manifestam os interesses gerais dos Estados-Nações e da classe dominante no poder, em particular, não de modo mecânico, mas, sim, por meio das contradições entre capital e trabalho, capital e tecnologia, trabalho e produção, trabalho e educação, que se manifestam no seio, tanto de países de capitalismo central, quanto de capitalismo dependente.

Neste sentido, o papel dos organismos supranacionais, em geral, e do BM, OCDE e UNESCO, em particular, e, mais recentemente, do MERCOSUL e da União Europeia, tem sido essencial na elaboração e difusão da ideologia desenvolvimentista e educativa em nível mundial, normatizando, controlando e

\footnotetext{
${ }^{4}$ Sobre a ideologia da modernização ver Cardoso (2006).
} 
legitimando a produção do conhecimento considerado vital para a conservação do capitalismo. Por detrás de suas orientações e recomendações encontra-se o interesse de longo prazo da burguesia na manutenção do poder político ${ }^{5}$ : manutenção da política macroeconômica, redução do antagonismo entre capital e trabalho, (con) formação para o trabalho explorado e alienado, bem como administração dos conflitos intraburgueses.

Reconhecendo as desigualdades econômico-sociais, educacionais, tecnocientíficas dos diferentes Estados-Nações, e delas partindo, os organismos supranacionais buscam combiná-las e integrá-las em suas particularidades e contradições, impulsionando o desenvolvimento desigual e combinado da sociedade capitalista, cuja tática se desvela no movimento e realização internos do telos da estratégia.

Um não se faz e ou se fortalece sem ou contra o outro. BM, OCDE e UNESCO, em particular, remetem uns aos outros para referendar as concepções utilitárias e instrumentais da ideologia do desenvolvimento capitalista e de formação do capital humano em todos os níveis de ensino. Desse modo, nosso foco de análise está na medição do BM, OCDE e UNESCO junto ao Estado.

É importante dizer, em tempo, que foge ao escopo desse texto a análise pormenorizada da farta documentação emanada pelos organismos supranacionais. A partir dessas considerações, buscamos, tão somente, reunir elementos para afirmar que estes organismos são mediação do capital no processo de uniformização, integração e subordinação da produção do conhecimento ao processo histórico de internacionalização da economia, sob os ditames do capital.

\footnotetext{
${ }^{5}$ Cabe destacar o trabalho minucioso da Comissão Trilateral (EUA, Europa, Japão), que, há quase quarenta anos, está à frente da administração do capital global. Criada em julho de 1973, por iniciativa de David Rockefeller, figura de proa do capitalismo norte-americano e, formada por 120 representantes do bloco americano (EUA, Canadá e México), 170 do bloco europeu (países-membros da UE) e 105 do asiático (Japão, Coreia, China e países do Pacífico), todos donos do capital privado, não ocupantes de cargos na burocracia estatal, a referida Comissão tem como finalidade promover a internacionalização da economia, aumentar a produtividade e intensificação do trabalho com base na competitividade dos mercados. Cf. http://www.trilateral.org/.
} 


\section{BM, OCDE, UNESCO: AÇÕES E RECOMENDAÇÕES DOS ELEMENTOS DE UM PARTIDO POLÍTICO EM TORNO DA INTERNACIONALIZAÇÃO DA EDUCAÇÃO/CONHECIMENTO}

A ciência e tecnologia em suas múltiplas dimensões - seja em sua componente ideológica, seja em seu caráter fetichista, ou ainda, como mito da modernidade - vem sendo caracterizada pelos organismos supranacionais por um certo determinismo que tem na organização da produção e na gestão da força de trabalho o resultado de um imperativo tecnológico. Invoca-se o debate sobre a transição, quer para uma sociedade do conhecimento, quer para uma sociedade coesa, igualitária e democrática, cujo motor estaria na produção de ciência, tecnologia e, particularmente de inovação. Quanto maior a inovação, maiores as transformações econômicas e sociais.

Portanto, na visão do capital e de seu partido político, torna-se necessário fomentar a inovação, acelerar a produção do conhecimento científico-tecnológico em escala mundial, o que depende da produção de pesquisa em áreas tidas como estratégicas, realizada em universidades, em laboratórios de pesquisa e desenvolvimento (P\&D) de empresas ou por meio da parceria de ambos, universidade e empresa; e, ainda, promover maior interação dos fluxos de informação, tecnologia e pessoal qualificado.

Trata-se de uma resposta concreta aos processos de internacionalização da economia e da tecnologia, que, em sua dinâmica, torna indispensável a educação, particularmente a formação do trabalhador coletivo em sua face internacionalizada.

No período compreendido entre o pós-Segunda Guerra e o de implantação e implementação das políticas neoliberais é possível verificar que a influência de organismos como o BM, CEPAL, MERCOSUL e UNESCO se sobressai em países da América Latina, em geral, e no Brasil, em particular, enquanto a OCDE vem marcando atuação decisiva porém, ainda, não aparente.

\subsection{A UNESCO}

A UNESCO, órgão de consultoria e coordenação para assuntos financeiros, técnico-metodológicos e pedagógicos das reformas educativas, 
tendo como mote a educação permanente, toma para si a tarefa de difusora "da cultura e da educação da humanidade para a justiça, a liberdade e a paz" na suposta linha de frente de criação de uma nova ordem internacional.

Suas propostas respeitantes aos diferentes níveis e modalidades de educação abarcam a estrutura dos diversos sistemas educativos, bem como as articulações entre formação geral, formação profissional e ensino superior, podendo ser resumidas nos seguintes aspectos: universalização progressiva da educação básica; democratização do acesso ao ensino superior; melhoramento da qualidade e eficácia do ensino, em geral, e do pessoal docente, acompanhados de mecanismos de avaliação com ajuda externa; adaptação do ensino profissional e ensino superior ao mercado; reforma das instituições de ensino; modernização curricular.

No Brasil, a representação da UNESCO, principal agência das Nações Unidas para a educação, se estabelece no início do governo militar em um contexto histórico em que as reformas educacionais vinham sendo fortemente balizadas por recomendações oriundas dos acordos MEC-USAID.

Estes acordos MEC-USAID inseriam-se num contexto histórico de alinhamento do governo brasileiro ao imperialismo norte-americano, sendo fortemente pautados pelo tecnicismo produtivista da teoria do capital humano, com o objetivo de orientar políticas e técnicas das reformas educacionais brasileiras à luz do desenvolvimentismo do país bem como, do processo de internacionalização da economia nos marcos da divisão internacional do trabalho. Os referidos acordos tiveram papel decisivo no processo de reforma da educação brasileira, em geral, e na reforma universitária, em particular.

Nesse período, os convênios assinados com a UNESCO não oferecem, ainda, a possibilidade de o Organismo apresentar um plano de educação completo, mas, apenas, realizar pesquisas que apontassem os problemas educacionais nos planos regional e nacional ${ }^{6}$, bem como, na área cultural, no que diz respeito à cooperação para a conservação, preservação e restauração do patrimônio cultural (UNESCO, 1981).

\footnotetext{
${ }^{6}$ O convênio firmado, no ano de 1966, entre UNESCO e Universidade para o Desenvolvimento do Estado de Santa Catarina, é analisado com rigor por Aguiar (2008).
} 
Entretanto, será a partir do ano de 1982 que a UNESCO passará, mais concretamente, a intervir na realidade educacional brasileira. O Acordo Geral de cooperação técnica em matéria educacional e científica, apontando para o fortalecimento dos laços de cooperação entre Brasil e UNESCO, prevê a cooperação para o desenvolvimento de atividades consideradas prioritárias pelo governo, de acordo com as linhas de atuação estabelecidas pela UNESCO em suas conferências, relatórios, etc.

Em tempos de abertura política, o fortalecimento da associação dependente e consentida do governo brasileiro ao imperialismo passa a combinar coerção com persuasão, envolvendo representantes das instituições de ensino para compor o grupo executivo do acordo, a exemplo do Grupo Intersetorial de Coordenação (GIC), constituído para auxiliar a UNESCO e o Governo na execução do Acordo, que teve a seguinte composição: o Secretário Geral do Ministério; o Chefe do Departamento de Cooperação Cultural, Científica e Tecnológica do Ministério das Relações Exteriores; o Secretário de Cooperação Econômica e Técnica Internacional da Secretaria de Planejamento da Presidência da República; o Representante do Conselho Nacional de Desenvolvimento Científico e Tecnológico (CNPq); o Representante do Conselho de Reitores das Universidades Brasileiras; o Representante do Instituto Brasileiro de Educação, Ciência e Cultura (IBECC); o Representante da UNESCO no Brasil (BRASIL/DAI, 1982).

É possível afirmar que os termos de Recomendações emanadas, anteriormente, nos anos de 1962 e 1963, estiveram presentes no Acordo Geral, assinado em 1981, bem como em documentos exarados pelo Conselho Federal de Educação (MEC/CFE) da década de 1970 e pela Secretaria de Ensino Médio e Técnico (MEC/SEMTEC) dos anos de 1990, como por exemplo, o estabelecimento de três níveis de ensino, na formação profissional - "ensino para a formação de trabalhadores qualificados", "ensino para a formação de técnicos" e "engenheiro e quadros superiores" —, além de sustentar uma relação entre educação e desenvolvimento tecnológico ${ }^{7}$.

\footnotetext{
7 Silveira (2010) destaca que a Recomendação Internacional sobre Ensino Técnico e Profissional elaborada pela UNESCO, em 1962, propunha a educação para a vida em uma era tecnológica, orientando os sistemas nacionais de ensino a elaborar planos de ensino técnico e profissional destinados a formar pessoal para os três setores da economia, nos três níveis de ensino (fundamental, médio e
} 
No período de implantação das políticas neoliberais a intervenção da UNESCO, no Brasil, ganha fôlego, sob os auspícios da Declaração Mundial sobre Educação para Todos, realizada em Jomtien, Tailândia, de 5 a 9 março de 1990, cuja meta "viável" é a Satisfazer as Necessidades Básicas de Aprendizagem (NEBAS), as quais compreendem tanto os instrumentos essenciais para a aprendizagem (como leitura e escrita, expressão oral, cálculo, solução de problemas), quanto os conteúdos básicos da aprendizagem (conhecimentos, habilidades, valores e atitudes), necessários para que os seres humanos possam sobreviver, desenvolver plenamente suas potencialidades, viver e trabalhar com dignidade, participar plenamente do desenvolvimento, melhorar a qualidade de vida, tomar decisões fundamentadas e continuar aprendendo (UNESCO, 1990).

Os fundamentos do projeto de educação em nível mundial, determinadas na Conferência Mundial sobre Educação para Todos ${ }^{8}$, encontram boa acolhida por parte dos denominados "arautos da reforma" (SHIROMA; EVANGELISTA, 2002, p. 82-6), tornando possível que o Acordo Geral de 1981 fosse retomado. No ano de 1993, no governo Itamar Franco, tendo como ministro da Educação e do Desporto Murílio de Avellar Hingel, foi assinado o primeiro plano de trabalho, realizado conjuntamente com o MEC, cuja finalidade foi elaborar o Plano Decenal de Educação para Todos (1993-2003).

Com Silva Jr. (2002), afirmamos que o Plano Decenal de Educação para Todos é a expressão brasileira de um movimento maior, o da agenda globalmente estruturada de educação (DALE, 2004), orquestrado pela UNESCO, assessorado e financiado pelo BM, assumido pelo bloco no poder. Movimento este que resultou na reforma educacional brasileira, promovida, na segunda metade dos anos de 1990 e início dos 2000, em todos os níveis e modalidades de educação, a partir de diretrizes curriculares, referenciais

superior). Em fevereiro de 1963, o Conselho Federal de Educação/MEC aprovou o parecer que originou os cursos de engenharia de operação. Como se sabe, essa modalidade de ensino destinava-se à formação de engenheiros voltada para atividades práticas, enquanto que o trabalho intelectual (planejar e projetar) ficava a cargo de engenheiros com formação plena.

${ }^{8} \mathrm{O}$ governo civil-militar legou à Nova República um quadro educacional funesto: aproximadamente $30 \%$ da população era analfabeta; o índice de evasão e repetência aproximava-se de $50 \%$; $23 \%$ dos professores eram leigos. Com estes índices, o Brasil integrou o grupo dos países com maior taxa de analfabetismo (E-9), na Conferência de Jomtien, tendo que se comprometer a promover políticas públicas de educação a partir do Fórum Consultivo Internacional de Educação para Todos. 
curriculares, parâmetros curriculares nacionais, produzidos de forma hábil por intelectuais orgânicos do capital - empresários, pesquisadores e professores universitários -, afinados com o poder público, em todas as áreas de ação do Estado, particularmente a da educação.

Com a ascensão de Fernando Henrique Cardoso à Presidência da República, em 1995, as "posições consensuais" dos organismos supranacionais são assumidas e aprofundadas. Na realidade, o governo FHC, com base no tripé da plataforma de política neoliberal, iniciada no governo Collor de Mello - aprofundamento da abertura comercial, privatização de empresas e de serviços públicos, desregulamentação das relações de trabalho -, apropriando-se dos novos paradigmas tecnológicos, efetiva alterações significativas na educação, envolvendo as políticas públicas de avaliação institucional e educacional, o funcionamento dos sistemas de ensino, suas concepções, o currículo dos cursos, etc.; de seu turno, o trabalho respondia, predominantemente, às pressões das transformações econômicas e tecnológicas com elevação e persistência das taxas de desemprego, proliferação de oportunidades ocupacionais com condições de trabalho de pior qualidade, cristalização dos baixos rendimentos das massas.

Pode-se afirmar que a reforma empreendida no governo Cardoso traduz, fielmente, as propostas apresentadas pelo Diretor Geral da UNESCO, Federico Mayor, por ocasião do colóquio internacional $E$ o desenvolvimento, realizada em Paris, no ano 1994, incorporadas ao Relatório Educação - um tesouro a descobrir, coordenado por Jacques Delors, publicado no ano de 1996, cuja nota introdutória é de Paulo Renato de Souza, então Ministro da Educação.

Vale destacar, também, o compromisso coletivo assumido para se atingir os objetivos e metas de Educação para Todos, assinado no ano de 2000, n'O Marco de Ação de Dakar, que destacava como essencial que, novos compromissos financeiros concretos fossem firmados pelos governos nacionais, doadores bilaterais, multilaterais, incluindo-se o Banco Mundial, os bancos regionais de desenvolvimento, a sociedade civil e as fundações privadas (UNESCO, 2000).

No que mais nos interessa, desde o final da década de 1970 e início da de 1980 que a UNESCO vem intervindo no processo de reforma universitária, 
em geral, e do ensino superior, em particular. Junto a outras entidades internacionais (como o MCE, OMS, OEA, OCDE, FAO, Conselho Internacional de Educação de Adultos, Associação de Universidades de Língua Francesa, Associação Internacional de Universidades e Associação Internacional de Professores), a UNESCO, em 1977, no seminário sobre A contribuição prática dos estabelecimentos de ensino superior ao desenvolvimento das comunidades, já apontava para questões que se encontram presentes nos debates sobre a reforma universitária no Brasil.

Às funções da universidade, postas em relevo sobretudo no que diz respeito ao desenvolvimento econômico mundial, bem como o regional, no sentido de favorecer a instauração de uma nova ordem econômica internacional, outras foram, e vem sendo, acrescentadas: aumentar o nível cultural e profissional das populações numa perspectiva de educação permanente; realizar pesquisa na solução de problemas prioritários no desenvolvimento econômico; prestar serviços sob a forma de estudos, consultoria e pesquisa, colocar à disposição do público [leia-se setor privado] grupos de pessoas, laboratórios, computadores, meios de pesquisa, documentação, infra-estrutura sanitária ou esportiva, etc. (UNESCO, 1977 apud DIAS, 1981) ${ }^{9}$.

Para que a universidade possa dar conta de seu encargo, a UNESCO postula a descentralização geográfica das instituições; reestruturação dos estabelecimentos de ensino superior; diversificação, reorientação e reorganização dos programas de ensino e de pesquisa numa perspectiva interdisciplinar; adaptação dos métodos pedagógicos a novas clientelas de estudantes; reforço da ligação ensino, pesquisa e produção e relações mais estreitas com os meios da indústria e da agricultura; participação nas funções de ensino de especialistas não pertencentes ao quadro docente tradicional; informação do grande público sobre as instituições de ensino superior e participação das coletividades em suas atividades (UNESCO, 1977 apud DIAS, 1981).

\footnotetext{
${ }^{9}$ Marco Antonio Rodrigues Dias foi Diretor da Divisão do Ensino Superior da UNESCO em Paris, no período 1981-1999 e, exerce o cargo de consultor internacional e conselheiro do reitor da Universidade das Nações Unidas, desde 1999.
} 
A década de 1990 é profícua para a UNESCO no que se refere à produção de conferências, seminários e relatórios sobre o ensino superior, tais como a Conferência sobre Liberdade Acadêmica e Autonomia Universitária (1992), o Documento de Política para a Mudança e o Desenvolvimento na Educação Superior (1995), o Congresso Mundial sobre Educação Superior e Desenvolvimento de Recursos Humanos para o Século XXI (1997), a Conferência Mundial sobre o Ensino Superior no século XXI: visão e ação (1998), a Declaração sobre a Ciência e o Uso do Conhecimento Científico, firmada na Conferência Mundial sobre Ciência de Budapeste (1999) e publicada no ano de 2003, no Brasil, sob o título A ciência para o século XXI: uma visão e uma base de ação. Mais recentemente, citamos a Conferência Mundial sobre Ensino Superior 2009: as novas dinâmicas do Ensino Superior e Pesquisas para a Mudança e o Desenvolvimento Social.

Cabe destacar que, a Conferência Mundial da Educação Superior, realizada em Paris, no mês de outubro de 1998, deslanchou o processo de discussão sobre a rentabilidade dos negócios educativos, culminado na IV Reunião Ministerial da OMC, realizada em Doha, no Catar, em novembro de 2001. Naquela oportunidade, foram apresentadas propostas sobre as normas que deveriam ser mantidas ou aplicadas em todos os campos de negócios para a liberalização do comércio internacional da educação. "Pelas regras deste fórum, cada país participante apresenta a outro, demandas de abertura de mercado, segundo áreas de interesse. O Brasil elencou as suas, recebendo outras em troca, como a de abertura do setor de ensino superior" (UNESCO, 2004, p. 15).

Esta Conferência Mundial da Educação Superior, do ano de 1998, bem desvela a política da UNESCO de apoiar e incentivar ações que possam contribuir para a integração regional de blocos econômicos. Não é a esmo que, por ocasião do Protocolo de Intenções entre UNESCO e MERCOSUL, no ano de 1997, Frederico Mayor destacou que uma das respostas mais eficazes para viabilizar a "globalização" seria a formação de blocos regionais que, começando por acordos de natureza econômica, se converteriam, também, em pactos políticos e civilizatórios no sentido de promover avanços nos planos educacional, cultural, científico e tecnológico. 
A Representação da UNESCO no Brasil tem participado do processo de integração regional nas áreas da educação, ciência e da cultura, seja como parte integrante que é de um organismo supranacional, seja porque o representante no país é, também, o coordenador do programa de educação UNESCO/MERCOSUL, cuja sede localiza-se no Brasil.

O discurso de racionalização dos recursos, autonomia e avaliação institucional, consoante os documentos acima referidos, vem se materializando, desde os governos FHC, passando pelos mandatos de Lula da Silva, na contrarreforma universitária, por meio de mecanismos de credenciamento de cursos, reconhecimento de títulos de graduação, avaliação e autoavaliação institucional, e, ainda, financiamento das atividades de formação e de pesquisa.

Ainda no governo FHC, a UNESCO foi convidada pela CAPES para elaborar o Informe sobre Educação Superior no Brasil, publicado no ano de 2002, como parte do relatório geral sobre o Ensino Superior na América Latina, organizado pelo IESALC ${ }^{10} /$ UNESCO, sendo que o Relatório Final, Internacionalização da Educação Superior no Brasil, veio a ser publicado no ano de 2004, já no mandato de Lula da Silva.

É interessante notar que, neste mesmo ano de 2004, a OCDE desencadeia um estudo de análise comparativa da educação superior em 38 países, que se estenderá até o ano de 2008, cuja finalidade é enfatizar o papel do ensino superior como motor da competitividade numa economia com base "no conhecimento internacionalizado" e sustentado pela pesquisa científica e "competitiva em nível global". "The imperative for countries is to raise higherlevel employment skills, to sustain a globally competitive research base and to improve knowledge dissemination to the benefit of society" (OCDE, 2008a, p.4).

Considerando que a política de cooperação entre os países, em matéria de educação, ciência, tecnologia e cultura, tem ocorrido, predominantemente, no ensino superior de graduação e na pós-graduação, é neste setor que a IESALC/UNESCO, em atenção às negociações do $\mathrm{GATT}^{11}$, nos marcos da

\footnotetext{
${ }^{10}$ Instituto Internacional para a Educação Superior na América Latina e Caribe.

11 Para o GATT, o setor de serviços educacionais abrange educação "primária", "secundária", "póssecundária", e "terciária", além da educação profissional e da educação de jovens e adultos. Tendo como objetivo principal diminuir as barreiras comerciais, que no caso dos serviços educacionais podem estar associadas aos subsídios dos governos ao setor, à importação de material escolar, à necessidade de
} 
OMC, encontra maior possibilidade de comercialização dos "serviços educacionais".

$\mathrm{Na}$ visão dos organismos supranacionais, o ramo do ensino superior concentra as melhores oportunidades de comercialização de serviços pelas seguintes razões: em muitos países, o ensino superior não é financiado pelo fundo público; a "clientela" pertence às camadas economicamente mais favorecidas da população; o ensino superior destina-se, também, às demandas da "educação ao longo ensino", atendendo ao aprimoramento profissional requerido pelas corporações multinacionais

Em linhas gerais, as recomendações do referido Relatório estiveram presentes nos debates e seminários promovidos pelo primeiro governo Lula da Silva, salientando as transformações do ensino superior na sua relação com a política de ciência e tecnologia (C\&T), inseridas na perspectiva dos processos de internacionalização da economia e da tecnologia. Neste sentido, segundo sua posição de destaque no âmbito do MERCOSUL, o Brasil deve ampliar o debate sobre programas de cooperação - sul-sul e sul-norte, particularmente com a União Europeia -, no campo educacional, científico e tecnológico, além de propor um estudo censitário sobre a dinâmica das instituições de ensino superior que permita captar os fluxos de estudantes por nível de estudo, de maneira a ter uma dimensão real dos processos em curso. Este tipo de censo deve orientar-se para o mercado interno (intra-regional e inter-regional) e externo (IESALC/UNESCO, 2004, p. 8-9).

Diferentemente da cooperação internacional institucionalizada, historicamente, por meio de acordos bi e multilaterais, que envolvia interesses históricos, culturais, científicos e tecnológicos, na produção do conhecimento desinteressado, a internacionalização da educação, em geral, e do ensino superior, em particular, vem sendo posta e imposta pelos organismos

vistos, reconhecimento e revalidação de diplomas, aos obstáculos e ou exigências no processo de autorização para funcionamento de instituições de ensino, cursos e sistemas de creditação, bem como na celebração de convênios, o GATT entende que os serviços educacionais podem ser oferecidos tanto nas modalidades de educação à distância e educação presencial, mantendo-se ou não a instituição sede no país receptor; quanto por meio de programas de mobilidade estudantil; venda de "produtos" oriundos de pesquisas, além da oferta, por especialistas, de cursos, palestras, oficinas, etc. 
supranacionais, por mediação do Estado e de blocos econômico-regionais, em prol dos interesses imediatos do capital.

\subsection{A OCDE}

Organismo sucessor da Organização Européia de Cooperação Econômica (OECE), criada em 1948 no contexto de aplicação do Plano Marshall, que em sua origem tinha ações limitadas ao espaço geográfico da Europa, Estados Unidos e Canadá, a, atual, OCDE volta-se para a "cooperação e desenvolvimento econômicos" de diversos países do globo ${ }^{12}$, dedicada à elevação das taxas de emprego, estando seus trabalhos sobre educação estreitamente ligados à ação governamental, particularmente, nos setores da economia e emprego, com foco na formação do capital humano.

A abordagem do conceito de capital humano e da educação como fator de desenvolvimento econômico, no âmbito da OCDE, é coetânea à Teoria do Capital Humano desenvolvida por um grupo de economistas neoclássicos da Escola de Chicago, particularmente, Milton Friedman (1955), Jacob Mincer (1958), Gary Becker (1960) Theodore Schultz (1961), Edward Denison (1962), entre outros, propugnando sua aplicação na educação formal em todos os níveis de ensino.

A Teoria do Capital Humano foi difundida largamente pelos Estados Unidos, com a publicação de The economic value of education, de Theodore Schultz, em 1963, e de Human Capital: a Theoretical and Empirical Analysis, with Special Reference to Education, de Gary Becker, em 1964. Tornadas referências, essas publicações tiveram forte influência nas políticas educacionais dos anos 1960-70, levadas a cabo na maioria dos países da

\footnotetext{
12 Os países membros na origem da OCDE, nos anos de 1960 são: a Alemanha, a Áustria, a Bélgica, o Canadá, a Dinamarca, a Espanha, os Estados Unidos, a França, a Grécia, a Holanda, a Irlanda, a Islândia, a Itália, o Luxemburgo, a Noruega, Portugal, o Reino Unido, a Suécia, a Suiça, e a Turquia. Os restantes países tornaram-se membros posteriormente: Japão (1964), Finlândia (1969), Austrália (1971), Nova Zelândia (1973), México (1994), República Checa (1995), Hungria (1996), Polônia (1996), Coréia (1996), República Eslovaca (2000), Chile (2010), Eslovênia (2010), Israel (2010). Outros países como o Brasil, China, Indonésia, Índia, África do Sul e a Rússia vêm mantendo laços estreitos com a Organização, materializados na participação de comitês. Do bloco da UE, a Comissão das Comunidades Européias tem participação nos trabalhos da Organização (Artigo $13^{\circ}$ da Convenção da OCDE).
} 
OCDE, em geral, e países da América Latina, em particular, membros da $\mathrm{ONU}^{13}$.

A questão da educação como fator determinante do crescimento econômico assume estatuto de legitimação científica e econômica, dado o clima de euforia que marcava a expansão dos sistemas educativos no final dos anos 1960 e início doas 1970. Definido como um fator que reúne a saúde física e mental do indivíduo, talentos individuais inatos, habilidades e competências adquiridas pela educação formal, não-formal e, ainda, pela capacitação em serviço, o conceito de capital humano encontra boa acolhida em programas de outras agências internacionais como a UNESCO e o Banco Mundial, tornandose central para a padronização das estratégias de modernização e desenvolvimento econômico, a partir dos anos de 1970.

Contando com a doação dos 23 países mais ricos no Comitê de Ajuda ao Desenvolvimento, cujos maiores doadores são Estados Unidos, França, Alemanha, Grã-Bretanha e Japão, a OCDE tem, no âmbito da educação, suas atividades desenvolvidas por quatro setores. Dois deles, Comitê de Educação e $C E R I$, atuam no mesmo domínio, cabendo ao primeiro estudar dilemas e perspectivas das políticas de expansão no que concerne ao desenvolvimento da ciência e à formação dos quadros científicos e técnicos articulados aos objetivos econômicos e sociais da Organização, marcados pelo princípio da cooperação internacional; por sua vez, ao segundo compete promover, apoiar e desenvolver atividades de pesquisa, com base em levantamento de dados e indicadores internacionais, acerca dos sistemas nacionais de ensino, no que diz respeito ao desempenho dos alunos, à educação geral, formação profissional e inserção no mercado de trabalho, à caracterização das escolas. Tem a finalidade, em suma, de influenciar as decisões políticas internas nos países, bem como promover a comparação no plano internacional. Já o terceiro setor, o $C E L E / P E B$ destina-se à aplicação do programa de construção e instalação predial e aquisição de equipamento, com vistas ao uso eficaz e eficiente dos recursos materiais utilizados nas instituições de ensino; o quarto e último setor, não menos importante, o IMHE- Gestão Institucional do Ensino

\footnotetext{
${ }^{13}$ Na década de 1970, Schultz levou adiante a Teoria do capital humano quando publicou Investment in Human Capital: The Role of Education and of Research (1971) e Human Resources (Human Capital: Policy Issues and Research Opportunities) (1972).
} 
Superior reúne representantes de instituições de ensino superior e de governos tendo em vista elevar a competitividade regional com base na pesquisa $\mathrm{e}$ inovação realizadas no ensino superior.

Com base no desenvolvimento e análise quantitativa de indicadores internacionais comparáveis, a OCDE, junto à UNESCO, vem alavancando não apenas a padronização da educação, contribuindo, assim, na formulação da agenda globalmente estruturada para a educação, mas também no processo de internacionalização do conhecimento, mediada pelo mecanismo de Classificação Internacional Padronizada da Educação (ISCED) ${ }^{14}$, concebida pela UNESCO nos anos de 1970.

Revisada e atualizada, conjuntamente, pela UNESCO, OCDE e Eurostar no ano de 1997, a ISCED97 ${ }^{15}$ tem sido utilizada oficialmente, no Brasil, pelo INEP e pelas IES, desde o Censo 2000 para classificar instituições, cursos e programas da educação superior.

Os últimos relatórios da OCDE têm revelado uma preocupação marcante, por parte do capital, em questões políticas relacionadas à natureza das atividades de pesquisa, à mobilidade internacional dos pesquisadores e cientistas e ao ritmo da produção de inovação, com base na ideologia da sociedade do conhecimento.

Na América Latina, em geral, e no Brasil, em particular, a intervenção da OCDE é bem recente se comparada à Europa, em geral, sendo, portanto, pouco visível. A fim de continuar exercendo sua hegemonia na economia mundial, a OCDE vem buscando reforçar seus laços com países não-membros, a exemplo do Brasil que, embora não seja membro pleno do organismo em todos os comitês, vem estreitando sua relação com a Organização desde o início da década de 1990. Nos governos Lula da Silva (2003-2010), esta aproximação se deu no sentido de um "engajamento ampliado" como passo prévio à "adequada adesão" do "parceiro emergente" (OCDE/ICTSD, 2007) ${ }^{16}$.

\footnotetext{
${ }^{14} \mathrm{Em}$ alguns documentos a tradução de International Standart Classification for Education é colocada como Classificação Internacional Normalizada da Educação, a exemplo do Gabinete de Planejamento, Estratégia, Avaliação e Relações Internacionais do Ministério da Ciência, Tecnologia e Ensino Superior (MCTES/GPEARI) de Portugal. No Brasil, usa-se, de modo coloquial, a sigla CIPE.

${ }^{15}$ Cf. UNESCO: Institute for Statistics, disponível em: http://www.uis.unesco.org/ev.php?ID=3813 201\&ID2=DO TOPIC .

${ }^{16}$ Souza (2009) analisa as implicações da relação entre Estado brasileiro e OCDE na formação e trabalho docentes.
} 
Dos 250 comitês e grupos de trabalho, o Brasil tem participação ativa em 15 deles: Conselho Diretivo do Centro de Desenvolvimento; Comitê do Aço, Conselho Diretivo do PISA; Fórum Global sobre Transparência e Troca de Informações para fins Fiscais; Comitê da Agricultura e órgãos subordinados; Comitê de Política Científica e Tecnológica e órgãos subordinados; Comitê de Estatísticas e órgãos subordinados; Comitê de Competição e órgãos subordinados; Comitê de Comércio e órgãos subordinados; Comitê de Investimento; Comitê de Governança Publica; Grupo de Trabalho sobre Corrupção em Transações Comerciais Internacionais; Órgãos subsidiários do Comitê de Políticas para a Educação; Grupo de Experts ad hoc conjunto do IEA/NEA sobre os Custos de Geração Elétrica; Comitê de Política Ambiental; Conselho Diretor da Administração Institucional na Educação Superior; Grupo de Trabalho sobre Previdência Privada (OCDE/CENTRO DE COOPERAÇÃO PARA NÃO MEMBROS, s/d. Negritos nossos).

Os Estudos Econômicos, publicados com um lapso que varia de um ano e meio a dois anos para cada um dos países membros, não tem a mesma periodicidade para os países não-membros. Os Estudos Econômicos da OCDE: Brasil foram publicados nos anos de 2001, 2005, 2006 e 2009, enquanto que Perspectivas econômicas da América Latina, vem sendo publicada, anualmente, desde 2007.

Afinada com o BM e a UNESCO, a OCDE também possui um amplo leque de ação em temas como a política macroeconômica, reforma política de setores da microeconomia, acordos sobre o comércio de aeronaves civis, concorrência aperfeiçoada, liderança na governança corporativa, fim do sigilo bancário, combate à corrupção, regras empresariais, uso eficiente de energia, meio ambiente, mapeamento da captura e armazenamento de carbono, assistência aos idosos, saúde, inclusão financeira para aumento do índice da população de classe média, sindicatos ${ }^{17}$ e educação.

Sendo "um dos principais atores na era da globalização" (OCDE, 2001, p. 1), o Brasil, depois de ter promovido um amplo processo de

\footnotetext{
17 Inserida no processo de enfraquecimento dos sindicatos combativos a relação Comitê Sindical para a OCDE e Central Única dos Trabalhos (CUT) têm sido, para o capital, eficaz na "disseminação de boas práticas" e, por conseguinte, na (des)organização e (des)conscientização da classe trabalhadora no Brasil.
} 
desnacionalização e desindustrialização, manteve, nos governos FHC e Lula da Silva, a estabilidade macroeconômica; fortalecendo o ajuste fiscal; construindo a credibilidade das metas de inflação; promovendo maior desenvolvimento dos mercados financeiros, mormente ao que se refere à expansão de crédito ao consumidor, financiamento habitacional e agrícola; avançando na reforma previdenciária, faltando, apenas, "dar prioridade à redução das generosas aposentadorias e pensões dos servidores públicos e privilégios" (OCDE, 2001, p. 7); aprimorando as políticas sociais focalizadas e, ainda, como não poderia deixar de ser, participando ativamente do processo de internacionalização da educação, particularmente, no nível superior de ensino.

Neste sentido, a intervenção da OCDE no Brasil ocorre particularmente por mediação da tabela ISCED97, do PISA $^{18}$, da PIAAC, do TALIS, além dos relatórios Education at a glance ${ }^{19}$, nos quais a Diretoria de Educação da OCDE, por meio de indicadores comparáveis internacionalmente, traça o perfil do nível educacional da população matriculada nos três níveis de ensino e diferentes modalidades de educação.

Longe de apenas levantar dados e indicadores, a Organização envolvese diretamente nas "questões e tendências" da educação superior, cuja abordagem da internacionalização do ensino superior insere-se numa perspectiva de caráter contraditório, encoberta no bojo de inúmeros debates capitaneados, ora pela UNESCO, ora pelo BM, ora pela própria OCDE, voltados para o papel do Estado, o desenvolvimento econômico e sócioambiental, assim como para as políticas públicas de educação e políticas de ciência, tecnologia e inovação.

Suas propostas e orientações vão ao encontro daquelas preconizadas pelos outros dois organismos: expansão de matrículas, diferenciação de instituições, diversificação da oferta, diversificação das fontes de financiamento, redefinição do papel do Estado na educação superior, prioridade aos objetivos da qualidade e da equidade, foco crescente na

\footnotetext{
${ }^{18}$ Lançado no ano 2000 pela OCDE, o Pisa tem como objetivo avaliar o conhecimento de jovens na faixa etária de 15 anos de idade, em três "domínios", quais sejam, letramento em leitura, matemática e ciências. Dentre os países participantes, além do Brasil, encontra-se Portugal. No Brasil, o órgão responsável pela aplicação e divulgação dos resultados do instrumento de avaliação é o INEP/MEC, órgão igualmente responsável na aplicação do SAEB, ENEM, ENADE.

19 Em português: Panorama educativo.
} 
responsabilidade e nos resultados, novas formas de governança institucional, implementação de rede mundial de instituições e de docentes e discentes, realce do papel do ensino superior na pesquisa e inovação, incentivo à mobilidade de estudantes e pesquisadores, adaptação da carreira acadêmica às mudanças, reforço dos laços com o mercado, formulação de estratégias de internacionalização da educação superior (OCDE, 2008).

\subsection{O Banco Mundial}

Desde a sua criação na Conferência de Bretton Woods, em 1944, ao Banco Mundial foi destinado o papel de prestar assistência técnica e financeira para a reconstrução da Europa Ocidental, tornado-se um dos instrumentoschave na difusão da ideologia da modernização e do desenvolvimentismo no pós $\square$ Segunda Guerra. Inscrito no projeto de hegemonia econômica, política e cultural dos Estados Unidos, o BM, lado a lado com o FMI, tinha, até o final da década de 1960, um caráter eminentemente economicista, concedendo empréstimos ao setor de infraestrutura dos países.

Nos anos de 1970, sob a presidência de Robert Mac Namara (19681980), o Banco incorpora a sua racionalidade funcional-econômica aspectos sociais e culturais, assumindo, desse modo, um caráter humanitário e missionário de combate à pobreza "con pasión y profesionalidad para obtener resultados duraderos, y ayudar a la gente a ayudarse a sí misma y al medio ambiente que la rodea, suministrando recursos, entregando conocimientos, creando capacidad y forjando asociaciones en los sectores público y privado" (BANCO MUNDIAL, s/d), a tal ponto que o relatório de 1974 é apontado como marco da modificação das linhas de ação do Banco em relação aos anos de $1960^{20}$.

\footnotetext{
${ }^{20}$ O Banco Mundial é parte integrante do Grupo Banco Mundial, dispondo de duas instituições, quais sejam, o Banco Internacional para Reconstrução e Desenvolvimento (BIRD) e a Associação Internacional de Desenvolvimento (AID). O Grupo Banco Mundial, portanto, incorpora, além destas duas instituições, mais outras quatro: Corporação Financeira Internacional (CFI), a Agência Multilateral de Garantia de Investimentos (MIGA), o Centro Internacional para Resolução de Disputas de Investimentos (ICSID) e o Fundo Global para o Meio Ambiente (GEF). A criação e incorporação desses setores, todos subordinados ao mesmo presidente, marcam, indelevelmente, sua forma de atuação e intervenção. Cf. (http://www.bancomundial.org/). Para maior entendimento da estrutura e divisão interna de trabalho do Grupo Banco Mundial e historiografia de suas atividades ver Pereira (2009).
} 
Por um lado, a gestão de McNamara dá continuidade a iniciativas e mudanças importantes promovidas por Woods; de outro, dinamiza, inova e expande as operações do Banco numa escala inédita, ampliando sua gravitação financeira, política e intelectual e consolidando-o, definitivamente, como uma agência fulcral no âmbito das políticas de desenvolvimento, em geral, (PEREIRA, 2009, p. 112) e, de financiamento das reformas educacionais promovidas nos países de capitalismo dependente, alocando um montante cada vez maior de verbas na rubrica da educação, particularmente no campo da formação profissional (LEHER, 2005).

O BM articula conceitos de viés economicista, como produtividade, qualidade empresarial, competitividade, eficiência, eficácia com outros de cunho sócio-humanitário, como equidade, inclusão social e coesão social, intervindo, de modo particular, no ajuste estrutural dos países de capitalismo dependente de acordo com o rearranjo da economia mundial e com a reconfigurada divisão internacional do trabalho.

Portanto, sua atuação/intervenção difere de país para país de acordo com a carteira e desempenho econômico de cada Estado-Nação, assumindo um caráter de influência mais programática, mais consensual, no caso de países de capitalismo central, e de influência fortíssima, chegando à imposição de políticas, por meio de Programas de Ajustamento Estrutural, no caso de países de capitalismo dependente.

Com um amplo leque de ação em temas como a política macroeconômica, reforma política de setores da microeconomia, redução da pobreza, saúde, meio ambiente, e, mais recentemente, corrupção, as diretrizes do BM no campo educacional são: focalização do gasto público no primeiro segmento de ensino da educação básica; formação profissional aligeirada e instrumental; ênfase na diferenciação entre instituições e cursos no nível superior de ensino; introdução do sistema "de custo compartilhado", particularmente no ensino superior; privatização e mercantilização da educação em todos os níveis e modalidades.

A partir do conceito de governabilidade, o Banco vem direcionando e apoiando a descentralização de governo, particularmente nas políticas e programas sociais, buscando fortalecer a integração "vertical" nas áreas de 
saúde, educação e políticas de proteção social nas esferas federal, estadual e municipal.

Além de financiamentos e condicionalidades no sentido de provocar maior liberalização e desregulamentação mediadas pelas parcerias públicoprivadas $^{21}$, a estratégia do Banco, tal como as da OCDE e UNESCO, inclui um programa de estudos, conferências e assistência técnica em áreas como desenvolvimento metropolitano, desenvolvimento do mercado, crime e violência, envelhecimento, qualidade do emprego e educação.

A relação entre Brasil e BM vem desde 1949 (SOARES, 1999; PEREIRA, 2009), baseada na estratégia do Banco para atuar no Brasil articulada ao modelo de desenvolvimento econômico adotado historicamente pelos governos brasileiros.

O ano de 1980 pode ser tomado como marco da intervenção do BM no Brasil (ibid), não apenas, porque é ano em que os empréstimos ao país passam a fazer parte das análises internas do Banco, a partir da paridade dólares-cesta de moedas, o que altera os custos dos financiamentos e a natureza dos empréstimos, mas também, por ser nesta década que, os empréstimos do referido Banco passaram a contemplar projetos ambientais e a ampliar o financiamento para projetos nas áreas de educação, C\&T e saúde, aparentando, assim, certa prioridade do Banco em conceder empréstimos para essas três áreas (SOARES, 1999, p. 14-7). O documento Financiamento da educação nos países em desenvolvimento: uma exploração das opções políticas, de 1986, pode ser tomado como marco da intervenção do BM no setor educacional.

Entretanto, é nos anos de 1990, com a publicação da trilogia Educação primária (1990), Educação profissional técnica e capacitação (1991) e, Ensino superior: as lições da experiência (1994), que os policy papers do BM passam a exercer papel decisivo na privatização de políticas sociais, impondo a lógica da substituição do público pelo privado, para além da imposição do capitalismo

\footnotetext{
${ }^{21}$ O BM vem estruturando uma rede global de PPP com a finalidade de "An established global forum where public sector PPP practitioners exchange knowledge, innovations, and new developments"(Banco Mundial, 2010). Disponível em: http://wbi.worldbank.org/wbi/Data/wbi/wbicms/files/drupalacquia/wbi/WBI\%20PPP\%20Brochure.pdf
} 
norte-sul (LEHER, 1998) e do fortalecimento da cooperação Sul-Sul tendo o Brasil como testa de ferro do subimperialismo ${ }^{22}$.

No contexto de políticas liberalizantes, de mundialização do capital e internacionalização da tecnologia, tornam-se prioridade do BM a expansão de matrículas, a diferenciação de instituições, a diversificação das fontes de financiamento, a redefinição do papel do Estado na educação superior, a prioridade aos objetivos da qualidade e da equidade ao lado da educação básica. No mesmo sentido, suas publicações $\square$ Ensino superior: as lições da experiência (1994), Financiamento e gestão da educação superior: um relatório da situação das reformas no mundo (1998), Educação superior nos países em desenvolvimento: perigos e promessas $(2000)^{23}$ e, ainda, Construir sociedades do conhecimento: novos desafios para educação terciária $(2003)^{24}$ manifestam a preocupação marcante com a educação tecnológica de nível superior, incorporada ao discurso governamental, vista como um campo aberto à produção de inovações tecnológicas, bem como de novas possibilidades de comércio; além disso, destaca-se a importância da educação superior, em geral, para o desenvolvimento econômico, a integração na economia mundial e, sobretudo, a coesão social em torno das "estruturas de governança" (BANCO MUNDIAL, 2003, p. XXVIII).

A análise das reformas universitárias, em curso no Brasil e em Portugal, a partir da legislação (lei de educação, decretos, propostas de emendas constitucionais sobre a autonomia, contratos de gestão, projetos de

\footnotetext{
22 Destacam-se as diferentes esferas "geocomerciais" em que o Brasil vem se projetando desde o ano de 1994, coerente com o papel sub-imperialista: no âmbito sub-regional, o MERCOSUL; no continente americano, participou da Cúpula de Miami, cujo objetivo era o de configurar, até o ano de 2005, a área de livre comércio para as Américas (ALCA) envolvendo todas as economias do continente, à exceção de Cuba; em nível internacional, a relação com a OMC oscila entre a adesão e a resistência aos acordos da Organização, tendo criado suas tarifas fora das normas da OMC e um regime de comercialização independente, cujo objetivo é implantá-lo no âmbito do MERCOSUL (SILVA, 2004). No que diz respeito à comercialização da educação, a partir do Protocolo de Montevidéu, assinado no ano de 1997, os governos FHC e Lula da Silva buscaram encontrar, no âmbito do MERCOSUL, opções que valorizassem "os serviços educacionais" na dimensão da cooperação, por meio de programas específicos no CNPq e na CAPES.

${ }^{23}$ Relatório produzido pelo Grupo de Trabalho sobre Educação Superior - Task Force -, em conjunto com a UNESCO. Disponível em http://www.tfhe.net/report/downloads/download report.htm.

${ }^{24}$ Este Relatório incorpora o conceito de educação superior lançado pela OCDE, em 1999, no qual a "educação terciária" é um nível ou uma etapa de estudos posterior à educação secundária, portanto, póssecundário, cuja oferta é diversificada segundo o perfil institucional, que pode ser o de "universidades públicas y privadas, institutos de educación superior y politécnicos, así como en otros tipos de escenarios como escuelas de secundaria, sitios de trabajo, o cursos libres através de la tecnología informática y gran variedad de entidades públicas y privadas" (BANCO MUNDIAL, 2003, p. IX).
} 
desenvolvimento institucional, etc.), fontes de financiamento (montantes e percentuais sobre o PIB aplicados em educação superior pelo Fundo Público), bem como da natureza das IES, desvela a influência determinante das recomendações do BM, como já demonstrado por diversos estudos, entretanto, não sem referência as recomendações da OCDE e UNESCO. Afinal, BM, OCDE e UNESCO são elementos de um mesmo partido político que vem promovendo, historicamente, uma reforma intelectual e moral estritamente ligada ao programa de reforma econômica do capital.

\section{A GUISA DE CONCLUSÃO}

Neste texto buscamos evidenciar que a dinâmica tendencial da internacionalização da economia e de seu correlato, a internacionalização da tecnologia, requer a organização e aplicação de políticas científico-tecnológicas e políticas educacionais, no que os organismos supranacionais assumem papel decisivo não apenas nas orientações de ordem política, assistência técnica, metodológica e financeira no que diz respeito à "reestruturação", "modernização", "desenvolvimento econômico" e "democratização" dos Estados-Nações, "democratização da educação" e "internacionalização da educação superior", mas também a reforma cultural, intelectual e moral da sociedade.

Diferentemente dos anos de 1960-70, em que as orientações da OCDE e UNESCO, tendo a educação como fator de desenvolvimento econômico, se voltavam mais para as ações governamentais nos setores da economia e emprego, com foco na formação do capital humano, a partir do período de construção do consenso em torno da implantação das políticas neoliberais, os relatórios e orientações, não só da OCDE e UNESCO, mas também do BM passam a revelar preocupação, por parte do capital, com questões políticas relacionadas à natureza das atividades de pesquisa, a mobilidade internacional dos pesquisadores e cientistas, o ritmo da produção de inovação, com base na sociedade do conhecimento; e, ainda, à internacionalização da educação superior e de seu correlato, a pesquisa científico-tecnológica e de inovação.

A educação passa a cumprir papel coerente com os mecanismos de internacionalização da economia e da tecnologia, passando a responder não 
apenas àquela dinâmica em nível internacional, mas também em nível regional. Neste sentido, as reformas educacionais levadas à cabo por diferentes Estados-Nações, como no Brasil, têm como mediação principais os organismos supranacionais, particularmente UNESCO, OCDE, BM, bem como da associação estratégica entre MERCOSUL e União Européia.

\section{REFERÊNCIAS}

AGUIAR, Letícia Carneiro. A política educacional catarinense da década de 1960: educação, desenvolvimento e teoria do capital humano. Revista HISTEDBR on-line. Campinas: HISTEDBR, $\mathrm{n}^{\circ}$ 30, 2008, pp. 228-247. Disponível em: http://www.histedbr.fae.unicamp.br/revista/edicoes/30/art15 30.pdf.

BANCO MUNDIAL. Cerrando la brecha en educación e tecnologya. Estudios del Banco Mundial sobre América Latina y el Caribe. U.S.A.: The Word Bank, 2003. Disponível em

http://www.ocimed.gob.pe/documentos obs/lit gris/brechaedyytec baco mundial.pdf. BANCO MUNDIAL. Construir sociedades de conocimiento: nuevos desafíos educación terciária. U.S.A.: The Word Bank, $2003 . \quad$ Disponível em http://siteresources.worldbank.org/TERTIARYEDUCATION/Resources/Documents/Con structing-Knowledge-Societies/CKS-spanish.pdf.

BANCO MUNDIAL. Memorando e Recomendação sobre o Projeto de Educação Tecnológica. U.S.A.: The Word Bank, 1987. Disponível em http://wwwwds.worldbank.org/external/default/WDSContentServer/WDSP/IB/1987/06/25/0000092 65 3960926054820/Rendered/PDF/multi page.pdf. [Tradução livre nossa].

BANCO MUNDIAL. Memorando sobre o Portugal- Segundo Projeto de Educação (Loan 1793-PO). U.S.A.: The Word Bank, 1990. Disponível em http://wwwwds.worldbank.org/external/default/WDSContentServer/WDSP/IB/1990/11/07/0000092 65 3960924224003/Rendered/PDF/multi page.pdf.

BANCO MUNDIAL. Projeto treinamento e desenvolvimento de recursos humanos. U.S.A.: The Word Bank, 1984. Disponível em http://wwwwds.worldbank.org/external/default/WDSContentServer/WDSP/IB/1984/05/01/0000092 65 3970818102103/Rendered/PDF/multi page.pdf

BRASIL. Presidência da República. Decreto $n^{\circ}$ 87.522, de 25 de agosto de 1982. Promulga o Acordo de Cooperação Técnica em Matéria Educacional, Científica e Técnica, concluído entre Governo do Brasil e UNESCO, no ano de 1981. Brasília: DAI, 1982.

CARDOSO, Miriam Limoeiro. Ideologia do desenvolvimento - Brasil: JK-JQ. 2.ed. Rio de Janeiro: Paz e Terra, 1978.

CARDOSO, Miriam Limoeiro. Sobre as relações sociais capitalistas. In: LIMA, Júlio César; NEVES, Lucia Wanderley (Orgs.). Fundamentos da educação escolar do Brasil contemporâneo. Rio de Janeiro: FIOCRUZ, 2006.

CHESNAIS, François. A mundialização do capital. São Paulo: Xamã, 1996.

COGGIOLA, Osvaldo. Ecologia, biotecnologia e imperialismo. Revista Universidade e Sociedade: Brasília: ANDES, v. 39, 2005, p. 20-37.

COGGIOLA, Osvaldo. Perspectivas do complexo Educação/Ciência \&Tecnologia no Governo Lula. Eccos - Revista Científica. São Paulo: UNINOVE, no 2, v. 5, 2004, pp. 59-75.

COGGIOLA, Osvaldo. Universidade e Ciência na Crise Global. São Paulo: Xamã/Pulsar, 2001. v. 1. 
DIAS, Marco Antonio Rodrigues. Universidade em crise busca solução na integração com a sociedade (1981). Brasília: UNESCO, 1981. Disponível em: http://mardias.net/site2010/?page id=423

DALE, Roger. Globalização e educação: demonstrando a existência de uma "cultura educacional mundial comum" ou localizando uma "agenda globalmente estruturada para a educação"? In: Revista Educação e Sociedade. Campinas: UNICAMP: CEDES, vol. $25, \mathrm{n}^{\circ} \quad 87, \quad$ p. 423-460, maio/ago. 2004. Disponível em http://www.scielo.br/pdf/es/v25n87/21464.pdf.

GRAMSCI, Antonio. Cadernos do Cárcere, v.3. Maquiavel. Notas sobre o Estado e a política. 3.ed. Rio de Janeiro: Civilização Brasileira, 2007.

LEHER, Roberto. O BIRD e as reformas neoliberais na educação. Revista PUC viva [on line]. São Paulo: APROPUC, 1999, $\mathrm{n}^{-}$5. Disponível em http://www.apropucsp.org.br/revista/r05 r03.htm.

LEHER, Roberto. Wolfowitz no Banco Mundial: educação como segurança. In: Projeto de análise da conjuntura brasileira. Outro Brasil, 2005. Net. Disponível em http://www.outrobrasil.net/.

LIMA, Kátia. Contra-reforma na educação superior: de FHC a Lula. São Paulo: Xamã, 2007.

LIMA, Kátia. Educação a distância na reformulação da educação superior brasileira. In: Siqueira, Angela C. de; Neves, Lúcia Maria W. (Orgs.). Educação superior: uma reforma em processo. São Paulo: Xamã, 2006.

MARX Karl; ENGELS, Freidrich. Manifesto do Partido Comunista. São Paulo: Martin Claret, 2004.

NEVES, Lúcia Maria Wanderley. (Org.). Educação superior: uma reforma em processo. São Paulo: Xamã, 2006.

NEVES, Lúcia Maria Wanderley; PRONKO, Marcela Alejandra. O mercado do conhecimento e o conhecimento para o mercado. Rio de Janeiro: EPSJV, 2008.

OCDE. Brasil: para uma economia mundial mais forte, limpa e justa. Paris: OCDE/CCNM, s/d. Disponível em http://www.oecd.org/dataoecd/34/13/46532840.pdf.

OCDE. O Brasil e a OCDE: não de hoje, não é para amanhã. Paris, OCDE: ICTSD, V.3, n.4, 2007. Disponível em: http://ictsd.org/.

OCDE. Tertiary Education for the Knowledge Society. Paris: OCDE, 2008, Overview.

OCDE. Tertiary Education for the Knowledge Society - Thematic Review of Tertiary Education: Synthesis Report. Paris: OCDE, 2008a, v.1.

PEREIRA, João Márcio Mendes. O Banco Mundial como ator político, intelectual e financeiro (1944-2008). Niterói, 2009. 386f. Tese (Doutorado em História). Instituto de Ciências Humanas e Filosofia, Departamento de História, Universidade Federal Fluminense, Niterói, 2009.

SGUISSARDI, Valdemar. Políticas de Estado e Políticas de Educação Superior no Brasil: alguns sinais marcantes de dependência. In: MOROSINI, Marília Costa. MERCOSUL/MERCOSUR: Políticas e Ações Universitárias. Campinas: Autores Associados; Porto Alegre: Editora da Universidade, 1998.

SGUISSARDI, Valdemar. Rumo à universidade competitiva: na conservadora a universidade perde sua face, sua alma e sua identidade históricas. Revista Perspectiva. Florianópolis: UFSC, v.20, nº 02, 2002.

SGUISSARDI, Valdemar. Rumo à universidade mundial: e a universidade será feita à sua imagem e semelhança. In: SGUISSARDI, Valdemar; FRANCO, Maria Estela; MOROSINI, Marília Costa. Internacionalização, gestão, democrática e autonomia universitária em questão. Brasília: INEP, 2005.

SHIROMA, Eneida; MORAES, Maria Célia; EVANGELISTA, Olinda. Política educacional. 2. ed. Rio de Janeiro: DP\&A, 2002.

SILVA Jr., João dos Reis. Mudanças estruturais no capitalismo e a política educacional do governo FHC: o caso do ensino médio. Revista Educação \& Sociedade. Campinas: CEDES, v.23, nº 80, 2002, pp. 201-233. 
SILVEIRA, Zuleide Simas da. Concepções de educação tecnológica na reforma da educação superior: finalidades, continuidades, e rupturas - estudo comparado Brasil e Portugal (1995-2010). Niterói, 2011. 445f. Tese (Doutorado em Educação). Faculdade de Educação, Universidade Federal Fluminense, Niterói, 2011.

SILVEIRA, Zuleide Simas da. Contradições entre capital e trabalho: concepções de educação tecnológica na reforma do ensino médio e técnico. Jundiaí: Paco Editorial, 2010.

SIQUEIRA, Angela. C. de. A regulamentação do enfoque comercial no setor educacional via OMC/GATS. Revista Brasileira de Educação. Mai./jun./jul./ago., 2004, pp. 145-184.

SIQUEIRA, Angela. C. de.. As novas relações entre a universidade e a sociedade brasileira na era da revolução científico-tecnológica: o saber (poder) em disputa. Texto apresentado na 18a Reunião da ANPEd, 1995. Caxambu, MG: ANPEd, 1995.

SIQUEIRA, Angela. C. de. O plano nacional de pós-graduação 2005-2010 e a reforma da educação superior do governo Lula. In: SIQUEIRA, Angela C. de; NEVES, Lúcia Maria Wanderley (Org.). Educação superior: uma reforma em processo. São Paulo: Xamã, v. 1, 2006a, p. 107-124.

SIQUEIRA, Angela. C. de. Pós-graduação em educação e a internacionalização do conhecimento: direito ou serviço. Revista da Avaliação da Educação Superior. Campinas: Universidade de Sorocaba, v. 11, n. 2, 2006b, pp. 73-86.

SOARES, Ricardo Pereira. Dívida pública externa: empréstimos do BIRD ao Brasil. Texto para discussão no 642. Brasília: IPEA, 1999.

SOUZA, Thaís Rabello de. (Con)formando professores eficazes: a relação política entre o Brasil e a Organização para a cooperação e desenvolvimento econômico (OCDE). 2009. Dissertação (Mestrado em Educação) - Universidade Federal Fluminense, $\quad$ Niterói, $2009 . \quad$ Disponível em: http://www.uff.br/pos educacao/joomla/images/stories/Teses/thais\%20rabello.pdf.

UNESCO. Acordo Geral de 1981. Brasília: UNESCO, 1981. Disponível em: http://www.unesco.org/pt/brasilia/about-the-unesco-brasilia-office/.

UNESCO. Declaração Mundial Sobre Educação Para Todos - Satisfação das Necessidades Básicas em Aprendizagem. 1990. Paris: UNESCO, 1990. Disponível em : www.unesco.org.br/publicações.

UNESCO. Desenvolvimento da educação em Portugal - Ensino Superior. Relatório Nacional de 2004a, volume II. Lisboa, Pt.: PORTUGAL:MCIES, 2004. Disponível em http://www.ibe.unesco.org/International/ICE47/English/Natreps/reports/portugal part 4. pdf.

UNESCO. Para uma política da educação em Portugal. Lisboa, Pt.: Livros Horizonte, 1982. 